\title{
The heuristic musical computer technologies in the creativity of modern composers
}

\author{
Kateryna Fadyeyeva, doc. art, assist. prof., Professor of the General and Specialized Piano Department \\ NMAU n. a. P. I. Tchaikovsky Architect Gorodetsky street, 1-3 / 1101001, m. Kyiv-1, Ukraine \\ https://orcid.org/0000-0003-2329-469X, katefadeevapiano@gmail.com
}

\begin{abstract}
The purpose of the research is to study the heuristic trends of music computer technologies in the works of contemporary composers. The research methodology is to use musicological, systemstructural, logically-constructive and heuristic methods. This methodological approach allows analyzing the creativity of modern composers, in the projection of the heuristic music computer technologies use. The scientific novelty of the research is the presentation of the specificity of the author's modern technique of the Ukrainian composer Alla Zagaykevych, whose specificity has been determined by musical computer technologies. Conclusions. The use of heuristic music computer technologies in the works of contemporary composers and Ukrainian artist Alla Zagaykevich has shown that the existing software capabilities allow carrying out sound "experiments" aimed at the search for new means of musical expression, organic integration of electronic sounds with traditional acoustic instruments. This kind of integration of traditional directions with innovative ones opens up unlimited perspectives in the composers' creative work.
\end{abstract}

Keywords: heuristic musical computer technologies, electro-acoustic music, composer's creativity, serials, digital sound synthesis, algorithmic music.

$\begin{array}{lll}\text { Received: 07.12.2020 } & \text { Accepted: 12.01.2021 } & \text { Published: 03.02.2021 }\end{array}$

\section{Introduction}

Music computer technology provides a variety of software for their use in contemporary composing in the field of academic creativity.

The old stereotype that has accumulated over a long period of Ukrainian academic music development has a negative impact on the use of electronic means by academic composers.

It so happened that academic composers were hardly educated on the achievements of electronic (Western term - electroacoustic) music. The integration of electronics (its capabilities in the instrumental and acoustic fields) with academic direction (traditional acoustic instruments) enriches the composer's arsenal with unique instruments with significant artistic and expressive potential, means of sound imitation.

The relevance of the research topic is due to the nature of modern composer's thinking, updating of composer's techniques, search and combination of various sound expressive means in the context of heuristic music computer technologies.

Modern music computer technologies, digital synthesizers, samplers, digital sound processing tools allow to simulate sound space, to master the nature of acoustic micro processes, to work with sound vibrations and to simplify the process of traditional composer's creation.

The purpose of the research is to study the heuristic trends of music computer technology in the works of contemporary composers, in particular Ukrainian artist Alla Zagaykevych.

Presentation of the main material. Our historical retrospectives in the process of the emergence, development and evolution of music computer technology in our article indicate that computer technology began to be introduced into music practice from the 1960-s of twentieth century. Note that computer-aided creation and processing of material require a mathematically accurate definition of the problem or object with the input of all parameters and their boundaries. Starting in the mid-1950's, experimental research in the field of digital audio synthesis has been most intensively practiced in the United States. Advantages of computer sound synthesis consisted of finding new sounds, timbres, unlike traditional, higher stability of digital technology (using analog technologies, it was possible to change the sound under the influence of natural heating of the current resistance), as well as to accurately play and realize their own compositions without the involvement of performers and conductor.

Computer technology in the field of digital audio synthesis has enabled the composer to program virtual instruments with the help of computer tools. In addition, the benefits of digital technology also include 
the analysis of real sounds, sounds of traditional musical instruments with the possibility of their processing, transformation, modification and subsequent reproduction.

The conceptual platform of specific music representatives also shows interest in music computer technologies, their ideology being the integration of the expressive capabilities of traditional instruments with electronic and extra-musical sounds.

Subsequently, software engineers in collaboration with the musicians worked on the idea of embodying a musical idea with the possibility of formatting sheet music (score) by computer means. The research result at this stage was the concept of Data-card, which functioned under the following conditions where each sound corresponded to a set of parameters on a specific text line (sound is a line).

In the early 1950s, the first computer music program was created with the ability to perform the simplest digital audio synthesis. Thus, in the "Music 1" form of sound waves looked like a triangle and three parameters are frequency, amplitude and duration. In 1958, the Music 2 program was developed, which included 16 waveforms and allowed up to 4 independent voices to be processed. In the 1970s, a sophisticated version of Music 11 was created for DEC computers to provide digital audio synthesis with a variety of virtual instruments and sound analyzer features.

The period of the 1980's was marked by the emergence of the version of "Music 5" - GLM (Common Lisp Music), which was written in the programming language Lisp. However, this version has a significant disadvantage, since it requires the composer to know the syntax of the language. Unlike the Music 5 version, the Software version 11 Music is C-Sound has available syntax independent of the programming language.

It should be noted that the above programs are mainly focused on the problem of sound synthesis, further consideration will focus on the programs through which will be the composition of the work.

Among the tools used by the composers in working with the sound should be noted algorithmic, which is based on the management of the processes of generation, introduction of prescriptions and restrictions. An important role for the use of algorithms in electronic music was played by the serial technique, which became, so to speak, the forerunner of algorithmic music. In general, the composer creates thematic material and gives the computer typical algorithms for evolution, variation, imitation, transposition, motive development. The obtained results are edited by the composer and, if necessary, certain algorithms are reintroduced (creation of a new fragment, rearrangement of parties, etc.). In addition to the above method, the composer does not work with musical fragments of the score, but with algorithms that are constantly updated and form the individual language of the composer, a kind of composer's catalog of algorithms. Thus, among the computer technologies in the field of algorithmic music we should mention the method of Joseph Matthias Hauer (1883-1959). The composition, its micro and macro forms were designed in accordance with the programmed rules. This method required a large number of experiments to find the most successful option, which in the 1950's began to be selected by electronic computing. Considering the algorithmic way of composing music is imperfect, containing a considerable number of rules and conventions, composer Iannis Xenakis has created the work Achorripsis for 21 instruments. The basis of this composition was stochastic principles, in accordance with which the interaction of fragments of the work is carried out under the minimum number of logical conditions. The principles of this method are set out in his book «Formalized Music» (Chapter IV, Free Stochastic Music Using a Computer). It is the author's view that the use of artificial intelligence in the compositional process greatly accelerates the mathematical operations and necessary calculations to create stochastic music. This creates a library of algorithms for the individual composer language, which is constantly being updated and improved [2;6]. Rudolf Ruzichka developed and used computer programs of his own with the same methodology.

In the late 1960s, Dutch composer Gottfried Michael König created the PR1 program and its modification to PR2, which, so to speak, integrates both approaches. In the first program, the compositional process is carried out using algorithms, in the second program, a stochastic numerical generator changes the parameters of timbre, rhythm, tempo, altitude and volume independently of each other, the obtained random fragments were subsequently composed.

The idea of constructing musical material in an algorithmic way was continued in a new perspective program of experts in the field of music informatics D. Leach and D. Fitch "X composer", which was created using nonlinear dynamic systems, without the use of random numbers. So, for example, the rhythm analysis was supposed to be performed on a fractal (self-similar) model, and it was assumed that a certain condition would be fulfilled, under which the segment preceding the main event and the next should contain a constant (uniform) rhythm.

The fractal model is similar to a tree with "branches" and "shoots" that copy the shape of the branches. Low levels correspond to well-kept, clear rhythmic formulas, and with the transition to other 
levels means changes of rhythm occur. If a new duration is required, the algorithm multiplies the largest of the existing durations by a certain numerical factor. In this context, it should be noted that the described fractal model of D. Leach and D. Fitch assimilates with the "branching" processes of Russian mathematician A. Markov, who studied the text of A.S. Pushkin's "Eugene Onegin" by the method of probabilistic statistical analysis. The probabilistic characteristics of these processes in the future depend on the state in which the process is at a certain point in time and does not depend on how it has proceeded in the past, "the future depends on the past only through the present".

The generating processes of a musical theme by D. Leach and D. Fitch are based on a chaotic model. The notion of chaos is used to describe some types of nonlinear dynamical systems that are modeled as mathematical equations; their solution is a point in multidimensional space that reproduces the following solution. The chaotic model is significantly different from the stochastic one, since each point is the result of complex calculations. A certain sequence of points forms the orbit of the system; all the points of the orbit of a nonlinear dynamic system are interconnected with a single note of the melody. The orbit system controls the growth of the tree and the hierarchy of individual levels.

In the 1980s, American composer and programmer Heinrich Taube developed an algorithm program to create computer music, Common Lisp. The structure of the program allows to use both "stochastic" and random "algorithms" that are "programmed" for the intended result, that is, those that exclude chance. However, the main disadvantage of this program is the need to know the programming language, in fact, to work with this program you need to become a programmer.

In 1996, composer and programmer, associate professor at the Folkwang High School of Music, Marcus Lepper designed the Pentaprism program for Russian composer Alexei Rosen. Five independent parameters are processed by the functions of the program are rhythm, altitude, octave position, dynamics and articulation in accordance with the serial principle, but it should be noted that the ideology of the program in the work of algorithms prevents stochastic results.

Impulse, a dynamic plan of the composition created using one algorithm, devoid of the development process. To prevent this, the program provides an interactive control that switches one or more parameters simultaneously to another variant combination of elements. The computer-aided design of a composition requires a great deal of attention, resourcefulness and detailed processing of a "coreimpulse" that will envolve on the principle of repeated variations based on a certain algorithm. Pentaprism allows to experiment with any episodes, fragments or parts of a composition [3].

By the early 1970-s, the development of electronic music had brought to the composer's creativity both advantages and certain difficulties. It was a considerable number of electronic-acoustic studios, such as the studios of P. Schaeffer, Ia. Xenakis, K. Stockhausen, E. Artemyev, and many others that "embodied" the interests of the composer. The above factors led to the creation by Pierre Boulez in 1977 of the Institute for the Coordination of Music and Acoustics (Institut de recherché et coordination acoustique / musique - Center for Music, Research and Education in Acoustics and Music at the Georges Pompidou Center). The studies conducted by I.R.C.A. M'om are aimed at academic musical creativity, the work, carried out by the composer and sound engineer, who deals with the technical side of the embodiment of the creative concept (in particular, the selection of the necessary instruments' sounds, the acoustic properties of sound material) [4].

In our retrospective review, we have differentiated and analyzed the orientation of the stages of computer technologies' development, intended for academic composers.

Let us dwell on some aspects and specifics of the computer technologies use by academic composers, on the example of several works by contemporary Ukrainian composer Alla Zagaykevych. Her work, "Ausgesetzt auf den Bergen des herzens ..." ("Taken to the Top of the Heart"), written on the Rainer Maria Rilke's lyrics for soprano, organ and 16 strings. The structure of the work traces three sections, on the border of which the composer applies certain spectral chords. At the end of each section, the use of the bass, clarinet, double bass multifaceted chords transferred to the string orchestra allowed to create the so-called "spectral sound".

In instrumental parts, imitating a natural overtone, or "harmonic spectrum", the author places an octave interval (traditional orchestral duplication) in the lower part, and a cluster at the top. To reproduce a quarter of the tonal components of the spectrum, a sound altitude micro-interval is used, based on spectral technique * and a quarter ton and a half ton trills.

Example 1. Fragment of a score 


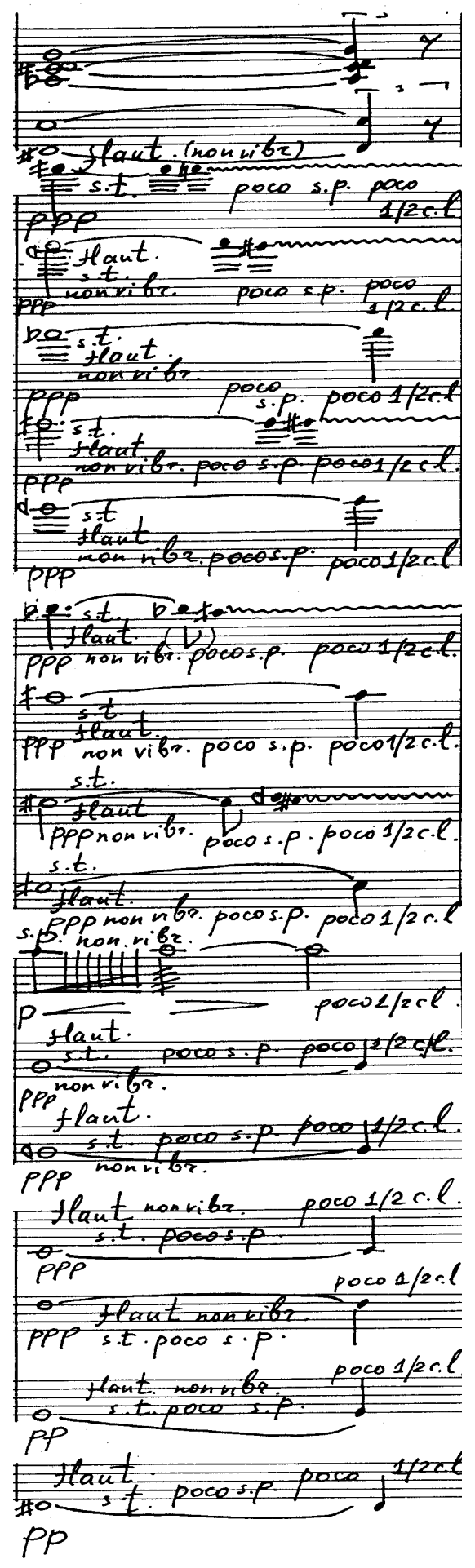

To work with the sound spectrum A. Zagaykevich uses the AudioSculpt program developed by the IRCAM Institute at the Pompidou Center, whose purpose is to analyze each sound very precisely. The program's capabilities allow to select the entire overtone composition at the sonogram level, listen to each overtone, and record exactly its amplitude (volume) and frequency (height). This information is transformed into sheet music after computer processing. 
Example 2. Fragment of a sonogram of the bassoon sound used in the work:

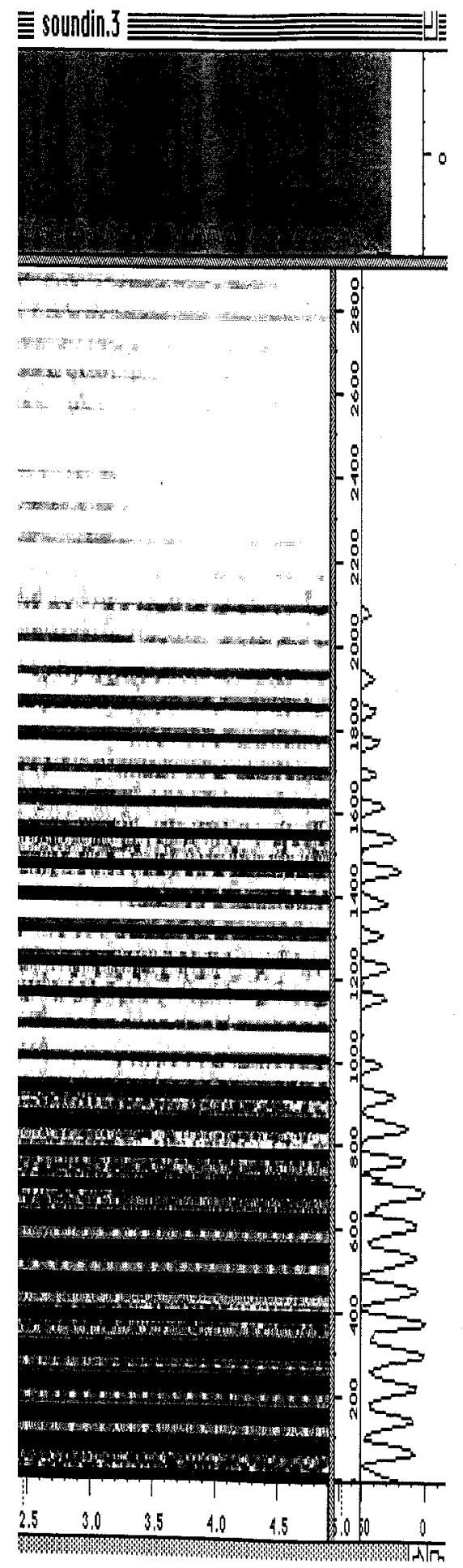

In the work "Air Mechanics" (sextet) A.Zagaykevich uses combinatorics as a general principle of composition's organization, in which sound and rhythmic events are integrated by a single idea. The composer represents the intonation model as a spatial microstructure extrapolated to all levels of musical tissue. Patchwork features use curve vectors as a modulator of the main audio material. When moving upwards, the trajectory tends to slow down and vice versa, when downward, its acceleration.

Example 3. Cello Party: 


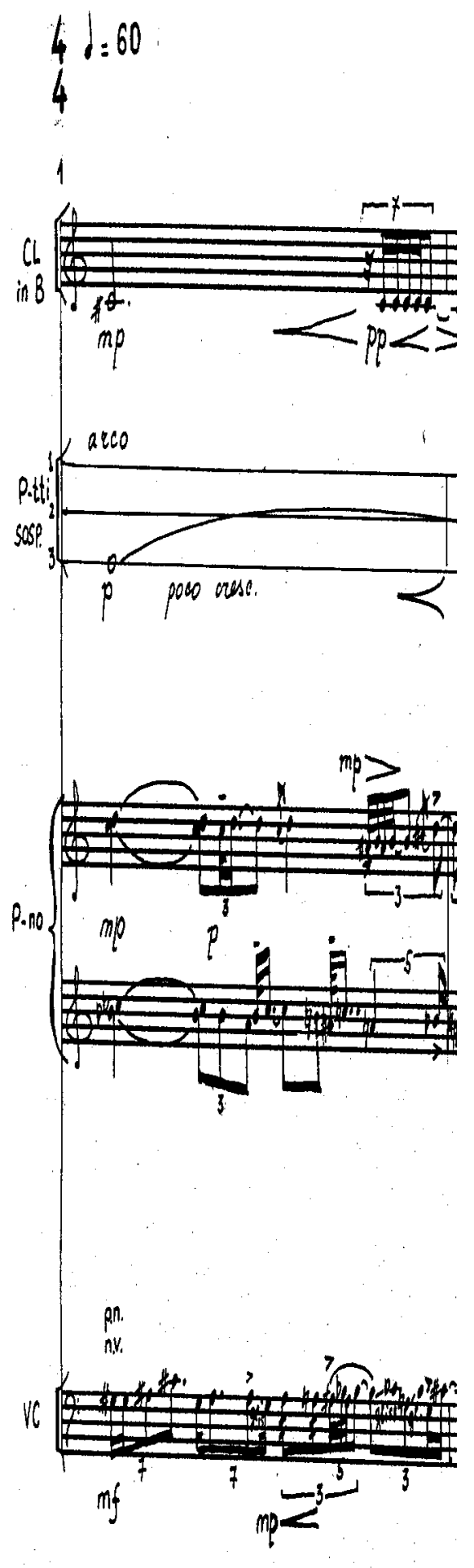

It should be noted that in the program with which the composer worked there is a wide possibility of integration of musical means (sound level, rhythm, interval proportions) on the basis of a single numerical system. In addition, the capabilities of the program allow to perfect each sound, to select its time, frequency and amplitude parameters, both vertically and horizontally with an approximation of up to $1 / 8$ tone.

An unusual sound palette is presented in the electro-acoustic work by A.Zagaykevich "music after the poem" "And by freezing, I will enter the celestial" based on Oleg Lishega's poem "Korop" for clarinet / bass clarinet, bassoon, double bass and electronic recording. The main metaphorical character of the composition is Carp, representative of the water depths; his image is associated with a certain closed, mysterious nature. The philosophical content of the work is the perversion of the person with the 
character of the animal, which becomes his "alter-ego", with him, so to speak, assimilated. The imaginary world of the poem needs adequate sound, timbre color, various techniques of composer technique.

The author used bass, bassoon and clarinet to create electronic sounds; however, to give them unusual timbre characteristics, new qualities, integration of the natural properties of these instruments with noise effects was carried out. For example, in a clarinet party, the multi-phonic spectrum (split sound) is sharp enough, defined; the bassoon party multifunction is more sophisticated, reflecting the relatively positive sphere; the bass part contains a number of different performing techniques, to create the impression of increasing the sound "mass" the composer introduces the technique of duplication of sound attacks.

In general, it should be noted that the instrumental part is saturated with sound effects that achieve special expression.

Example 4. Fragment scores:

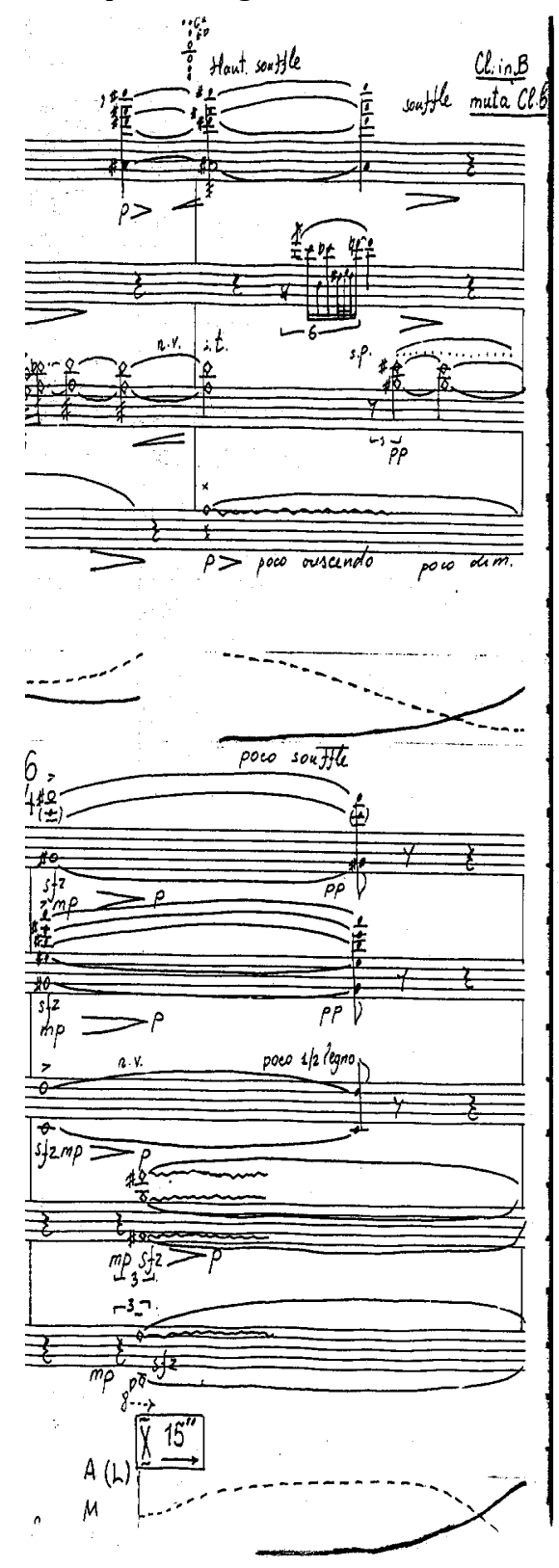

The electronic part of the work consists of 16 sections. In the course of performance, the conductor or one of the performers includes an electronic record through the MIDI system. In the electronic party, "noise effects" also have significant expressive meaning and dramatic load.

For example, the 8-section of an electronic party consists of a set consisting of 6 sounds synthesized in C-Sound based on a real wind record and a clarinet multifunction filter.

Example 5. Fragment of an electronic party. 


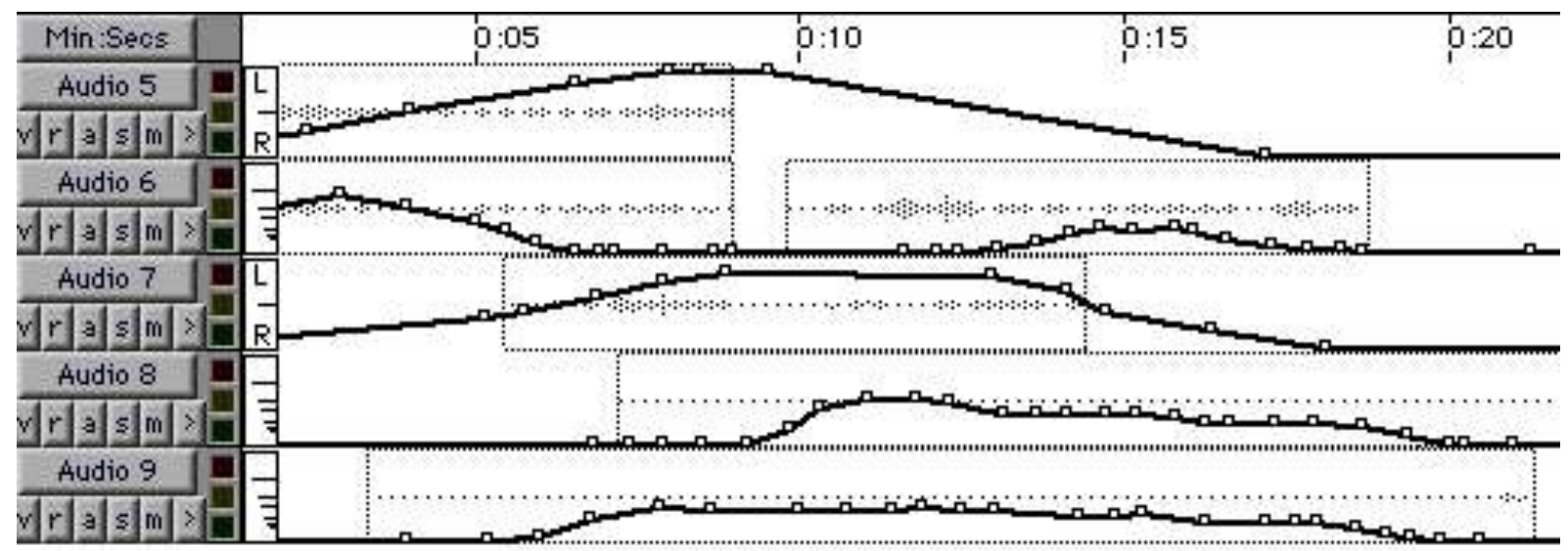

In the double bass ( 2 section), pizzicato, Arco - techniques processed in C-Sound, the synthesized sound was created on the basis of the bow motion on the strings with a discrete effect. This program contains a model of a frequency wave generator, which allows digital analysis of the received sound.

The work uses a new sound technology, namely, in section 1 the composer uses the technique of granular synthesis in real time, which is carried out by Max MSP algorithms. This process can be divided into two stages:

- first, we describe as a sampling session in which the first chord (cluster) of a work is processed. Its sound was changed by the technology of granular synthesis, i.e. movements of random granules, as well as filtering. The filtration process allows different overtones to be attacked;

- the second stage is related to the features of Max MSP, which performs real-time audio synthesis. Using a random number generator differentiates the granules depending on their size, which affects the "color", illumination of different overtones. This section had 16-channel sound with folding tones and sound specters.

The final stage of the compositional process was the digital multi-channel installation of audio material using Pro Tools (Digidisign).

At the present stage of the computer technology use in the study of music creativity has a multidimensional focus, as the software is created by teams consisting of world-class programmers and professionals in a particular subject area. The programs concentrate the results of many years' scientific research (referring to such knowledge-intensive problem areas as, for example, artificial intelligence, theory of information, theory of algorithms).

Before the emergence of intelligent systems, when the application was installed on the computer, the substantive side of the task disappeared, this paradigm changed with the emergence of intelligent systems. In music computer programs (academic direction, sound for recording, digital processing and synthesis, multichannel composing, timbre and rhythmic arrangement, training, heuristic) attention focused on intelligent algorithms.

The analysis of the use of heuristic music computer technologies in the works of contemporary composers, in particular Ukrainian artist Alla Zagaykevych, has shown that the existing software capabilities allow carrying out sound "experiments" aimed at the search for new means of musical expression, the organic integration of electronic sounds with traditional acoustic instruments. It is this integration of traditional trends with innovative ones that opens up unlimited perspectives on composer creativity.

\section{References}

1. Griezes, G. (2000). Strukturirovanie tembrov v instrumental'noj muzyke [Structuring timbre in instrumental Music]. Muzykal'naja akademija, 4, 113-120 [In Russian].

2. Kon, Yu. (1976). O teoreticheskoj koncepcii Janisa Ksenakisa [On the theoretical concept of Janis Xenakis]. In Krizis burzhuaznoj kul'tury i muzyka [Crisis bourgeois culture and music]. Issue 3. (pp. 106-134). Moscow, Muzyka [In Russian].

3. Rosen, A. (2000). Kriticheskij vzgljad na istoriju jelektronnoj muzyki [A critical look at the history of electronic music]. Muzykal'naja akademija, 4, 121-132 [In Russian].

5. Suslova, L. (1995). Proryv v novye zvukovye miry [Breakthrough in new sound worlds]. Muzykal'naja akademija, 2, 32-42 [In Russian].

6. Shutko, D. (2000). Pervye recepty spektral'noj kompozicii: Zherar Grize [The first recipes of the spectral composition: Gerard Griezes]. Muzykal'naja akademija, 4, 108-113 [In Russian]. 
7. Xenakis, Ia. (1971). Formalized a mathematics in composition. Bloomington; London, Indiana univ. press, cop. 